\title{
História da Vida no conteúdo textual de livros didáticos de Biologia do Ensino Médio
}

\author{
History of life in texts of High School Biology textbooks
}

\author{
Steve Allen Davi de Lima (steve.allen@aluno.uece.br) \\ Universidade Estadual do Ceará (Faculdade de Educação de Itapipoca - FACEDI-UECE) \\ Mário Cézar Amorim de Oliveira (mario.amorim@uece.br) \\ Universidade Estadual do Ceará (FACEDI-UECE e Mestrado Profissional em Ensino de Biologia em \\ Rede Nacional - PROFBio-UECE) \\ Daniel Cassiano Lima (daniel.cassiano@uece.br) \\ Universidade Estadual do Ceará (Centro de Ciências da Saúde - CCS-UECE e PROFBio-UECE)
}

\author{
Marcelo D'Aquino Rosa (marcelo.rosa@ifsc.edu.br) \\ Instituto Federal de Ciência e Tecnologia de Santa Catarina (IFSC)
}

Resumo: Considerando a problemática que envolve o ensino de Evolução Biológica (EB) nas escolas brasileiras, e que a História da Vida (HV) pode ser considerada como um tópico de EB que trata dos processos macroevolutivos responsáveis pelo surgimento dos grandes grupos de seres vivos, o objetivo dessa investigação é verificar quais conhecimentos acerca da HV são veiculados nos textos presentes em livros didáticos de Biologia do Ensino Médio, aprovados na edição de 2018, do Programa Nacional do Livro Didático (PNLD-2018). A partir da metodologia da análise de conteúdo, verificou-se que a maioria dos trechos selecionados aborda a HV na Terra a partir de intervalos de tempo, apresentando as principais mudanças físico-químicas e biológicas características de cada período. Foram identificados 23 eventos macroevolutivos distintos no material, com grande destaque para as extinções em massa, como também para a abordagem filogenética a partir de árvores da vida.

Palavras-chaves: Evolução Biológica; Macroevolução; Análise de Conteúdo; PNLD2018.

Abstract: Considering the problem that envolves the teaching of Biological Evolution on Brazilian schools and that the History of Life (HL) can be considered as a topic of Evolution that deals with the macroevolutionary processes, responsible for the emergence of large groups of living beings, the objective of this investigation is to verify what knowledge of HL is present on High School Biology textbooks approved on National Textbook Program (PNLD-2018). Using content analysis as a method, it was found that most of the selected sections address HL on Earth from time intervals, presenting the main physical, chemical and biological changes characteristic of each period. 23 distinct macroevolutionary events were identified in the material, with great emphasis on mass extinctions, as well as the phylogenetic approach from trees of life.

Keywords: Biological Evolution; Macroevolution; Content Analysis; PNLD-2018. 


\section{INTRODUÇÃOO}

A História da Vida (HV) é tema central no estudo das Ciências Biológicas, já que pretende traçar e explicar os processos pelos quais os organismos vivos evoluíram (BENTON, 2012), contemplando conhecimentos da Biologia Evolutiva e de fenômenos biológicos como a origem da vida, que geralmente provocam controvérsias no ensino de Biologia (OLIVEIRA, 2011).

Segundo Meyer e El-Hani (2005), é inadequado abordar a Evolução Biológica (EB) apenas como mais um conteúdo específico a ser ensinado, uma vez que a teoria evolutiva, como um arcabouço paradigmático, é fundamental na organização do pensamento biológico. Nessa perspectiva, embora a EB seja considerada o eixo integrador das Ciências Biológicas, percebe-se, no Ensino Médio brasileiro, que o currículo tradicional de Biologia ignora essa compreensão, de forma que os diversos temas deste componente curricular são tratados sem qualquer perspectiva evolutiva, e a EB fica praticamente restrita a um bloco isolado de conteúdo (COSTA, 2017), abordado ao final do último ano do Ensino Médio.

O tema HV é tratado, nessa investigação, como um tópico de ensino da EB. Além disso, é necessário enfatizarmos os limites temáticos e conceituais de interesse nesta pesquisa, pois quando se procura compreender, em um contexto mais abrangente, a temática HV, permeamos por assuntos como a Origem da Vida e os mecanismos e padrões que explicam a evolução nas escalas microevolutiva e macroevolutiva. Optouse, desse modo, por investigar o assunto relacionado à sua abordagem na forma textual em livros didáticos de Biologia do Ensino Médio, delimitando a temática dos processos ao nível macroevolutivo (evolução dos grandes grupos de seres vivos) da vida e suas concepções.

Vasconcelos e Souto (2003) reconhecem que o uso do livro didático (LD) em sala de aula ainda se constitui na principal estratégia de ensino nas escolas brasileiras. Em função disso, justifica-se que periodicamente sejam realizadas análises criteriosas desses livros com vistas a melhorar sua qualidade e torná-los mais acessíveis a professores e alunos. O Programa Nacional do Livro Didático (PNLD) tem feito análises periódicas dos livros didáticos que serão adotados pela rede pública de ensino; no entanto, as análises são gerais e não apresentam foco em temáticas específicas, persistindo a necessidade de investigações mais aprofundadas (VASCONCELOS; SOUTO, 2003). 
Nesse contexto, muitos professores e professoras da Educação Básica têm recusado adotar fielmente os LD lançados no mercado, na forma como são elaborados e distribuídos por autores e editoras. Esses professores fazem constantemente adequações para o uso desse recurso, tentando adaptá-los à sua realidade escolar e às suas convicções pedagógicas, o que acaba por reconstruir essa ferramenta didática (MEGID NETO; FRACALANZA, 2003). Nesse sentido, avaliar como os conhecimentos biológicos, os saberes científicos, estão apresentados nos LD é peça-chave de investigação e problematização de como a teoria está sendo abordada nesse que é um importante veículo de informação científica do país.

Oliveira (2011) enfatiza a importância da discussão do ensino de assuntos relacionados à "origem e evolução dos seres vivos" nas aulas de Biologia. Assuntos cuja abordagem de natureza científica frequentemente se depara com concepções e ideias de natureza não-científica, oriundas da trajetória de vida tanto de estudantes como também de professores. Essas concepções alternativas de fenômenos biológicos muitas vezes são influenciadas pelas investidas religiosas, que nos últimos anos vêm interferindo enormemente no ensino-aprendizagem dos conhecimentos biológicos. Nesse contexto, com essa investigação procuramos responder a seguinte questão de pesquisa: Quais conhecimentos acerca da HV estão presentes nos textos dos livros didáticos da disciplina escolar Biologia do Ensino Médio?

Esse texto é um recorte de uma investigação mais ampla que compôs o trabalho de conclusão de curso do primeiro autor, com o objetivo de verificar quais conhecimentos acerca da HV são veiculados nos textos presentes em livros didáticos de Biologia do Ensino Médio, aprovados na edição de 2018, do Programa Nacional do Livro Didático (PNLD-2018). Do qual procurou-se, especificamente, verificar frequência, atualidade e correção do conteúdo conceitual textual acerca da HV veiculado nessas obras distribuídas para as escolas públicas de todo o Brasil.

\section{DO COMPONENTE CURRICULAR BIOLOGIA À HISTÓRIA DA VIDA NO LIVRO DIDÁTICO DE BIOLOGIA}

O entendimento de como a disciplina escolar de Biologia foi constituída no País perpassa a compreensão de que qualquer currículo educacional em vigor é fruto de processos que envolveram conflitos sociais, rupturas e ambiguidades (GOODSON, 1995, TORRES, 2011). Dessa forma, são perceptíveis as fortes influências que o ensino de Biologia no Brasil teve dos modelos desenvolvidos nos Estados Unidos (EUA) nas 
décadas de 1960 e 1970, pela apropriação de projetos voltados para o ensino de Ciências, como os conhecidos manuais do Biological Science Curriculum Studies (BSCS) (SELLES, 2007).

A Biologia, como ciência, passa a ser reconhecida na década de 1960, sendo que apenas no ano de 1981 tem-se a publicação de um documento curricular (Plano Geral de Ensino - PGE) que a torna uma disciplina escolar no Brasil. Esse documento, intitulado como Plano Geral de Ensino (PGE), apresentava os objetivos, conteúdos e carga horária para cada uma das três séries do então denominado $2^{\circ}$ grau (TORRES, 2011). A partir da década de 1990, iniciativas como os Parâmetros Curriculares Nacionais (PCN) para o primeiro e segundo ciclos do ensino fundamental foram definidos pelo Ministério da Educação (MEC) (BONAMINO; MARTÍNEZ, 2002).

Os PCN ainda enfatizam que os professores, ao ensinarem Biologia, devem aguçar a curiosidade dos alunos através de conhecimentos já apreendidos e da busca de hipóteses sobre as problemáticas apresentadas e discutidas em sala de aula. $\mathrm{O}$ foco nesse aspecto é provocar o entendimento de que a disciplina não é um conhecimento acabado, mas progressivo, construído por teorias que podem ser complementadas ou descartadas (BRASIL, 1999).

Os documentos curriculares (BRASIL, 2006) estabelecem que o Ensino Médio deve abordar os temas da Biologia num contexto ecológico e evolutivo, tomando a interdisciplinaridade como eixo integrador. De maneira especial, a Evolução deve permear todas as disciplinas que constituem a Biologia (ZAMBERLAN; SILVA, 2009) “como elemento central e unificador" (BRASIL, 2006, p. 22). A nova Base Nacional Comum Curricular (BNCC) mantém, de certo modo, essa orientação, ao estabelecer 'Vida e Evolução' como uma unidade temática a ser contemplada pela área de Ciências da Natureza e suas tecnologias (BRASIL, 2017) no Ensino Médio, integrada pelos componentes curriculares de Biologia, Química e Física.

Dentre as competências exigidas para essa área, a BNCC orienta que alguns conhecimentos podem ser mobilizados e relacionados à $\mathrm{EB}$, registro fóssil, origem e extinção das espécies (BRASIL, 2017), ou seja, à abordagem da HV. Nesse sentido, Almeida e Falcão (2005) alertam que a compreensão dos conceitos relacionados à EB se mostra permeada por obstáculos epistemológicos, de fundo ideológico, filosófico e teológico, o que torna sua abordagem em contexto de sala de aula particularmente 
difícil, tanto no ensino, por parte dos professores, quanto na aprendizagem, por parte dos alunos.

Cicillini (1991) observou que os livros em geral seguem a mesma sequência, com poucas e irrelevantes variações entre si. Ilustrando essa questão, Carmo, Bizzo e Martins (2009) afirmam, a partir da análise de LD, que geralmente são consideradas apenas as teorias evolutivas de Darwin e Lamarck, não mencionando as contribuições de Alfred Russel Wallace, por exemplo, que também influenciaram a TE. Além disso, há problemas graves conceituais, tipo aqueles que associam "evolução" a "progresso" (FUTUYMA, 2006; BELLINI, 2006; ROMA, 2011).

No contexto de uma investigação com LD de Ciências para as séries finais do Ensino Fundamental, Rosa (2018) lista trabalhos anteriores para fundamentar a crítica que os LD podem, inclusive, contribuir para reforçar visões deformadas de ciência e do trabalho dos cientistas. Tratando de LD de Biologia para o Ensino Médio (EM), Carmo, Bizzo e Martins (2009) afirmam que "nessas obras, infelizmente, encontramos não somente erros conceituais, mas também históricos, a respeito da teoria da evolução biológica” (p. 210). Nesse sentido, é indispensável que o conteúdo conceitual de EB seja apresentado de forma correta e clara, de modo a contribuir para um melhor entendimento dos processos evolutivos tanto quanto da Natureza da Ciência (NdC).

A macroevolução é geralmente compreendida como o processo evolutivo em níveis acima da espécie, sendo principalmente estudada no registro fóssil, enquanto a microevolução estuda o processo evolutivo em curtos períodos de tempo. Eventos de processos macroevolutivos são muito mais propensos a levar milhões de anos, referindo-se a coisas como a origem de grandes grupos de seres vivos, eventos de extinções em massa, ou a explosão Cambriana (DIAS, 2008; RIDLEY, 2006). Provavelmente um dos maiores problemas em relação ao ensino da macroevolução, é a ênfase dada apenas à seleção natural e à mutação (ROCHA et al., 2007; BIZZO; ELHANI, 2009).

Costa (2017, p. 74) indica um conjunto de três conceitos/conteúdos que, na sua visão, são significativamente importantes para o correto ensino de macroevolução. São eles: 1 . Noção de tempo profundo; 2. Pensamento filogenético; 3. Relação entre micro e macroevolução. Essa ideia tem como base, além da diferenciação explícita das duas escalas evolutivas (micro e macroevolutiva), mostrando a relevância destas para o conteúdo de EB, a presença nos LD de Biologia desses três conceitos/conteúdos. 
De acordo com Cervato e Frodeman (2014), a respeito do primeiro conceito/conteúdo, é importante considerarmos uma diferenciação relevante de termos que, por vezes, se confundem: os termos 'tempo profundo' e 'tempo geológico'. Embora muitas vezes usados como sinônimos, o termo tempo profundo, elucidado por Thomas Carlyle em 1832, sendo mais tarde popularizado por McPhee, em 1981, define um vasto trecho do passado que vai além da cultura humana, ou seja, desde o final da fase formativa da Terra até os nossos dias. Já o termo tempo geológico destaca a maneira como os geocientistas contam o tempo. Neste âmbito, os milhares de anos da História da Terra são tratados de forma ordinária, em intervalos de tempo desiguais que marcaram as mudanças do seu meio físico e biológico, registrado nas rochas e na diversidade fossilífera nelas contida (CERVATO; FRODEMAN, 2014).

No contexto desta pesquisa os dois termos são válidos, uma vez que ambos se relacionam intrinsecamente na perspectiva da escala macroevolutiva. Gould (1987), por exemplo, relata que a teoria da evolução biológica seria impossível sem as dimensões de tempo geológico. A relação de fósseis e a datação geológica, sugeridas por Costa (2017), é importante, uma vez que a história demostra a ligação de ambas.

No que se refere ao segundo conjunto de conceitos/conteúdos, Costa (2017) define que o pensamento filogenético, que inclui a noção de ancestral comum recente e filogenia, é importante para a compreensão sobre conceitos e representações associados às relações de parentesco das espécies.

Nesse contexto, o pensamento filogenético, explicado à luz da sistemática filogenética, possibilita a síntese de uma grande quantidade de informação, como morfologia externa, embriologia, fisiologia e comportamento. Além disso, toda essa informação organizada em árvores evolutivas, também conhecidas por cladogramas ou filogenias, facilita a compreensão das relações de parentesco entre grupos biológicos baseadas na modificação de suas características através do tempo (MATIOLI, 2001).

Santos e Calor (2007) argumentam que, apesar de normalmente ser aplicada a estudos específicos de classificação biológica, a sistemática filogenética pode ser utilizada para enfrentar o paradigma essencialista no ensino de Biologia. O paradigma essencialista é aquele em que a evolução é tida como um pensamento linear, ou em escada, no qual os organismos "progridem" de formas simples para formas complexas. Diante disso, a sistemática filogenética reforça a ideia de que a melhor metáfora para a 
evolução é a da árvore da vida, ramificada, e não uma fila indiana progressiva que parte dos organismos mais "simples" até os mais "complexos" (SANTOS; CALOR, 2007).

Finalmente, a perspectiva de se abordar o último conjunto de conceitos/conteúdos - a relação entre micro e macroevolução - vai ao encontro da proposta de Costa (2017), que discute a importância de distinguir e relacionar tais processos, de modo a reconhecer que estas duas escalas da Evolução Biológica (EB) são conectadas de forma não linear e estão focadas em questões evolutivas distintas.

Segundo Ridley (2006), a especiação é a linha divisória tradicional entre micro e macroevolução. Huneman (2015) entende que, por ser o limite da análise microevolutiva e começo da macroevolutiva, a especiação pode ser o ponto em que estas duas escalas evolutivas se relacionam mais nitidamente. Contudo, Huneman (2015) alerta que a relação entre essas duas escalas é geralmente entendida de modo extrapolacionista, com base na ideia de que a escala macroevolutiva nada mais é que os processos microevolutivos levados a um intervalo de tempo superior ao geralmente considerado para esta última escala.

\section{PROCEDIMENTOS METODOLÓGICOS}

Nosso estudo alinha-se a uma abordagem qualitativa, que atende a questões particulares (MINAYO, 2001), com um viés interpretativo, muitas vezes caracterizado por "[...] um vaivém entre observação, reflexão e interpretação à medida que a análise progride" (GIL, 2002, p.90). Diante disso, pesquisas qualitativas requerem maior aproximação do pesquisador com os objetos de estudo, procurando construir resultados sempre comprometidos com os dados estudados, fato que contribui para a maior validade da investigação. Essa investigação também pode ser classificada como de cunho exploratório, pois teve "[...] como objetivo proporcionar maior familiaridade com o problema, com vistas a torná-lo mais explícito ou a constituir hipóteses" (GIL, 2002, p.41).

Para atingir o objetivo de verificar quais conhecimentos acerca da HV são veiculados nos textos presentes em livros didáticos de Biologia do Ensino Médio, aprovados na edição de 2018, do Programa Nacional do Livro Didático (PNLD-2018), buscamos apoio na metodologia de análise de conteúdo, que, segundo Bardin (1977, p. 38), “[...] pode ser considerada como um conjunto de técnicas de análise de 
comunicações, que utiliza procedimentos sistemáticos e objetivos de descrição do conteúdo das mensagens".

Após a delimitação do tema dessa investigação, do problema de pesquisa e da definição do objetivo, realizamos levantamento bibliográfico para fundamentar teórica e metodologicamente este trabalho. A etapa seguinte foi a delimitação dos conteúdos que abordam a HV, compreendida como a evolução dos grandes grupos de seres vivos ou macroevolução, presente nas dez (10) coleções de livros didáticos de Biologia do Ensino Médio, aprovadas na edição de 2018, do Programa Nacional do Livro Didático (PNLD-2018). No quadro 1 a seguir, apresentamos a lista dos LD analisados nessa investigação, a codificação utilizada para cada LD, o título da referida coleção, seus autores e a editora responsável pela publicação. Essa codificação foi criada a partir da ordem de apresentação das obras no Guia do Livro Didático do PNLD-2018 (BRASIL, 2017).

Quadro 1 - Livros Didáticos (LD) de Biologia utilizados na investigação.

\begin{tabular}{|c|c|c|c|c|}
\hline Código & Volume & Título & Autor/a(es/as) & Editora \\
\hline A1 & $1^{\circ}$ Ano & \multirow{3}{*}{ BIOLOGIA HOJE } & \multirow{3}{*}{$\begin{array}{c}\text { Fernando Gewandsznajder, } \\
\text { Helena Pacca e Sérgio } \\
\text { Linhares }\end{array}$} & \multirow{3}{*}{ Ática } \\
\hline A2 & $2^{\circ}$ Ano & & & \\
\hline A3 & $3^{\circ}$ Ano & & & \\
\hline B1 & $1^{\circ}$ Ano & \multirow{3}{*}{$\begin{array}{l}\text { INTEGRALIS- } \\
\text { BIOLOGIA: } \\
\text { NOVAS BASES }\end{array}$} & \multirow{3}{*}{ Nélio Marco Vicenzo Bizzo } & \multirow{3}{*}{ IBEP } \\
\hline B2 & $2^{\circ}$ Ano & & & \\
\hline B3 & $3^{\circ}$ Ano & & & \\
\hline C1 & $1^{\circ}$ Ano & \multirow{2}{*}{ আTिण } & \multirow{3}{*}{$\begin{array}{c}\text { André Catani, Antonio C. } \\
\text { Bandouk, Elisa G. Carvalho, } \\
\text { Fernando S. Dos Santos, } \\
\text { João B. Aguilar, Juliano V. } \\
\text { Salles, Lia M. Bezerra, } \\
\text { Maria M. A. De Oliveira, } \\
\text { Sílvia H. De A. Campos, } \\
\text { Tatiana R. Nahas e Virginia } \\
\text { Chacon }\end{array}$} & \multirow[b]{3}{*}{$\mathrm{SM}$} \\
\hline C2 & $2^{\circ}$ Ano & & & \\
\hline C3 & $3^{\circ}$ Ano & $\begin{array}{c}\text { SER } \\
\text { PROTAGONISTA } \\
\text { - BIOLOGIA }\end{array}$ & & \\
\hline D1 & $1^{\circ}$ Ano & \multirow{3}{*}{ BIOLOGIA } & \multirow{3}{*}{$\begin{array}{c}\text { César da Silva Júnior, Sezar } \\
\text { Sasson e Nelson Caldine } \\
\text { Júnior }\end{array}$} & \multirow{3}{*}{ Saraiva } \\
\hline D2 & $2^{\circ}$ Ano & & & \\
\hline D3 & $3^{\circ}$ Ano & & & \\
\hline E1 & $1^{\circ}$ Ano & \multirow{3}{*}{ BIO } & \multirow{3}{*}{$\begin{array}{c}\text { Sônia Godoy Bueno } \\
\text { Carvalho Lopes e Sérgio } \\
\text { Rosso }\end{array}$} & \multirow{3}{*}{ Saraiva } \\
\hline E2 & $2^{\circ}$ Ano & & & \\
\hline E3 & $3^{\circ}$ Ano & & & \\
\hline F1 & $1^{\circ}$ Ano & \multirow{3}{*}{$\begin{array}{c}\text { \#CONTATO } \\
\text { BIOLOGIA }\end{array}$} & \multirow{3}{*}{$\begin{array}{l}\text { Leandro Godoy e } \\
\text { Marcela Ogo }\end{array}$} & \multirow{3}{*}{ Quinteto } \\
\hline F2 & $2^{\circ}$ Ano & & & \\
\hline F3 & $3^{\circ}$ Ano & & & \\
\hline G1 & $1^{\circ}$ Ano & \multirow{2}{*}{$\begin{array}{l}\text { BIOLOGIA- } \\
\text { UNIDADE E }\end{array}$} & \multirow{2}{*}{ José Arnaldo Favaretto } & \multirow{2}{*}{ FTD } \\
\hline G2 & $2^{\circ}$ Ano & & & \\
\hline
\end{tabular}




\begin{tabular}{|c|c|c|c|c|}
\hline G3 & $3^{\circ}$ Ano & DIVERSIDADE & & \\
\hline H1 & $1^{\circ}$ Ano & \multirow{3}{*}{$\begin{array}{c}\text { BIOLOGIA } \\
\text { MODERNA- } \\
\text { AMABIS \& } \\
\text { MARTHO }\end{array}$} & \multirow{3}{*}{$\begin{array}{l}\text { Gilberto Rodrigues Martho e } \\
\text { José Mariano Amabis }\end{array}$} & \multirow{3}{*}{ Moderna } \\
\hline H2 & $2^{\circ}$ Ano & & & \\
\hline H3 & $3^{\circ}$ Ano & & & \\
\hline I1 & $1^{\circ}$ Ano & \multirow{3}{*}{$\begin{array}{l}\text { CONEXÕES } \\
\text { COM A } \\
\text { BIOLOGIA }\end{array}$} & \multirow{3}{*}{$\begin{array}{c}\text { Eloci Peres Rios e Miguel } \\
\text { Thompson }\end{array}$} & \multirow{3}{*}{ Moderna } \\
\hline $\mathbf{I 2}$ & $2^{\circ}$ Ano & & & \\
\hline I3 & $3^{\circ}$ Ano & & & \\
\hline J1 & $1^{\circ}$ Ano & \multirow{3}{*}{ BIOLOGIA } & \multirow{3}{*}{ Vivian Lavander Mendonça } & \multirow{3}{*}{ AJS } \\
\hline $\mathbf{J} 2$ & $2^{\circ}$ Ano & & & \\
\hline J3 & $3^{\circ}$ Ano & & & \\
\hline
\end{tabular}

Fonte: Elaborado pelos autores.

No passo de delimitação dos conteúdos, realizamos inicialmente uma leitura flutuante, constituinte da etapa de pré-análise de Bardin (1997), caracterizada como leitura superficial do documento a ser analisado. Após a seleção do LD e a delimitação do corpus de análise que aborda o tema em estudo, a etapa seguinte consistiu na exploração do material. Nessa etapa, utilizamos a categorização mista, com categorias estabelecidas a priori e a posteriori. A partir dessa delimitação, foram constituídas as seguintes categorias a priori, tendo como base teórica os estudos realizados por Santos e Calor (2007), Dawkins (2009), Benton (2012) e Costa (2017), a saber:

\section{Noção de tempo profundo}

Nessa categoria buscamos identificar, no corpus de análise, os conteúdos que tratam da história evolutiva dos grandes grupos de seres vivos, uma abordagem que contemple a relação das origens desses grupos, a compreensão dos milhares/bilhões de anos da história geológica da Terra, tratados de forma ordinária, em intervalos de tempo desiguais, que demarquem mudanças importantes do seu meio físico e biológico. Buscase aqui uma perspectiva que enfatize a relação de dados bioestratigráficos, da biologia molecular e da radioatividade na datação geológica.

\section{Eventos macroevolutivos}

Olhando para o passado evolutivo da Terra, deparamo-nos com importantes eventos que mudaram a dinâmica dos processos evolutivos dos grandes grupos de seres vivos, como, por exemplo, a Explosão do Cambriano, a diversificação das plantas terrestres durante o devoniano, a fauna de Ediacara no final do Neoproterozoico, a expansão do homem durante o pleistoceno e as bem estudadas extinções em massa, todos esses acontecimentos conhecidos como eventos macroevolutivos. A partir dessa categoria, buscamos identificar no corpus de análise a presença não só desses exemplos, 
como também verificar a influência, atribuída pelos LD, desses na formação dos principais grupos de seres vivos.

\section{Pensamento filogenético}

Com esta categoria, procuramos identificar nos conteúdos analisados abordagens que denotem a ligação evolutiva entre os diferentes grupos de seres vivos através da perspectiva de árvores filogenéticas. Diante desse contexto, o pensamento filogenético, tendo como base a sistemática filogenética, proporciona a síntese de uma grande quantidade de informações, presente algumas vezes de forma organizada em árvores evolutivas, os chamados cladogramas ou filogenias, facilitando a compreensão das relações de parentesco entre grupos biológicos baseadas na modificação de suas características através dos milhares de anos.

A partir do processo de análise, ou seja, a posteriori, a categoria 'Noção de tempo profundo' precisou ser subdividida em três subcategorias para melhorar o processo de análise, tendo em vista que não se excluem mutuamente:

\subsection{Relação de dados bioestratigráficos, moleculares e da radioatividade na} datação geológica

Diversos conhecimentos são importantes para a datação geológica. Dentre esses conhecimentos fundamentais, temos, por exemplo, os dados bioestratigráficos, onde os fósseis se inserem. Também temos os dados relacionados ao estudo da biologia molecular, exemplificados pelos fragmentos de elementos químicos como os ácidos nucleicos, e por fim, os dados da desintegração radioativa que alguns elementos rochosos apresentam. Procuramos, através desta subcategoria, identificar nos trechos de interesse a menção a algum desses tipos de conhecimentos considerados fundamentais na datação das rochas.

\subsection{Intervalos de tempo geológico}

O Tempo Geológico é subdividido em quatro intervalos denominados Eras (Précambriana, Paleozoica, Mesozoica e Cenozoica). Dessas, surgem subdivisões menores, denominados Períodos, que podem estes ser divididos também em Épocas (Séries) ou intervalos gerais. Diante disso, aqui os trechos versam, por exemplo, sobre a história evolutiva dos grandes grupos de seres vivos, correlacionando os eventos de origens desses a uma escala de tempo geológico. Em outras palavras, selecionamos os trechos que descrevem a História de Vida na Terra sendo identificada em intervalos de tempo e 
que apresente as principais mudanças no aspecto físico e biológico característico de cada período.

\subsection{Atualização do conteúdo}

Buscamos, com esta subcategoria, investigar nos trechos selecionados quais destes apresentam atualizações, ao conteúdo aqui investigado, especificamente no que se trata os períodos geológicos, comparando-os com a literatura especializada.

Da categoria 'Pensamento filogenético' emergem duas subcategorias que se excluem mutuamente, a saber:

\subsection{Linearidade do Pensamento filogenético}

Nesta subcategoria, os trechos apresentam a história evolutiva dos grandes grupos a partir de um pensamento linear, significando a origem de um grupo ou diferentes grupos de seres vivos pela ocorrência da transformação direta de um grupo 'A' em um determinado grupo 'B', denotando assim a evolução biológica como direcional e linear.

\subsection{Pensamento filogenético a partir de árvores da vida}

Os trechos nesta subcategoria evitam a perspectiva de linearidade em favorecimento de relações filogenéticas em "árvore", ou seja, apresentado o grau de parentesco entre espécies atuais e primitivas. O interesse nesta subcategoria foi encontrar ao longo das coleções trechos que abordassem a história evolutiva dos grandes grupos de seres vivos a partir do conceito de ancestralidade comum e de árvores da vida ou filogenéticas.

\section{RESULTADOS E DISCUSSÃO}

Dos 30 LD analisados, que compõem as dez coleções aprovadas na edição de 2018 do PNLD-2018, verificamos que 21 abordavam, de alguma forma, o tema HV. Quanto aos que não tratavam do tema, sete (07) livros são referentes ao primeiro ano do Ensino Médio (EM) e os outros dois (02) ao terceiro ano. Desse modo, verifica-se que todos os livros do segundo ano do EM abordaram a HV.

Essa distribuição vai ao encontro da organização curricular tradicional dos conteúdos conceituais de Biologia no EM, uma vez que os LD do segundo ano do EM geralmente abordam a biodiversidade, os sistemas morfofisiológicos (Morfofisiologia comparada e/ou humana) e os grupos de organismos (Taxonomia, Botânica, Zoologia, Microbiologia etc.), de modo que, quando a abordagem evolutiva está presente, enfatiza 
as narrativas macroevolutivas. Provavelmente devido a isso, esses foram os LD que mais apresentaram trechos sobre HV, com 124 trechos (54\%), seguidos pelos livros do terceiro ano, com 70 trechos (30\%), e os do primeiro ano, com 38 trechos (16\%) (Tabela 1).

Tabela 1 - Total de trechos textuais sobre HV identificados nos LD investigados

\begin{tabular}{c|c|c|c|c}
\cline { 2 - 5 } & \multicolumn{5}{|c}{ Quantidade de Trechos sobre HV } \\
\hline Coleções LD de Bio & $\mathbf{1}^{\mathbf{0}}$ Ano & $\mathbf{2}^{\mathbf{0}}$ Ano & $\mathbf{3}^{\mathbf{0}}$ Ano & Total por Coleção \\
\hline Coleção A & 34 & 14 & 0 & 48 \\
\hline Coleção B & 0 & 28 & 2 & 30 \\
\hline Coleção C & 0 & 27 & 16 & 43 \\
\hline Coleção D & 0 & 13 & 4 & 17 \\
\hline Coleção E & 0 & 7 & 1 & 8 \\
\hline Coleção F & 0 & 17 & 2 & 19 \\
\hline Coleção G & 3 & 1 & 0 & 20 \\
\hline Coleção H & 0 & 11 & 9 & 31 \\
\hline Coleção I & 1 & 1 & 29 & 12 \\
\hline Coleção J & 0 & 5 & 7 & $\mathbf{2 3 2}$ \\
\hline Total por Ano Letivo & $\mathbf{3 8}$ & $\mathbf{1 2 4}$ & $\mathbf{7 0}$ & \\
\hline Fonte: Elaborado pelos autores. & & & \\
\hline
\end{tabular}

Essa distribuição pode ser explicada pelo fato de a HV ser apresentada no EM restrita à abordagem da biodiversidade no planeta, sendo o estudo dos componentes da Biologia Evolutiva concentrado ao final do terceiro ano do EM, a despeito das orientações presentes nos documentos oficiais, tais como os PCN e a BNCC, e como já alertaram Meyer e El-Hani (2005).

Em relação às categorias formuladas aprioristicamente nessa investigação, os 232 trechos identificados distribuem-se da seguinte forma: 122 trechos (53\%) relacionados à 'Noção de tempo profundo', 70 trechos (30\%) relacionados a 'Eventos macroevolutivos' e 40 trechos (17\%) relacionados ao 'Pensamento filogenético'. A seguir, discutiremos os achados a partir de cada uma dessas categorias analíticas.

\subsubsection{Noção de tempo profundo}

A categoria mais frequente, correspondendo a 122 trechos, ou 53\% do número total de fragmentos. Os trechos encontrados descrevem a História de Vida na Terra, 
identificando os intervalos de tempo e as principais mudanças no aspecto físico e biológico característico de cada período. Também correlacionam dados das outras ciências para os processos de datação. Nitidamente fragmentada nos LD, essa categoria pode ser subdividida em assuntos que abordam pelo menos três temas: relação de dados bioestratigráficos, moleculares e da radioatividade na datação geológica; intervalos de tempo geológico; e atualização do conteúdo.

\subsubsection{Relação de dados bioestratigráficos, moleculares e da radioatividade na} datação geológica

Nesta subcategoria buscamos identificar, nos 122 trechos contabilizados na categoria principal, quais destes mencionavam conhecimentos importantes para a datação geológica. Dentre esses conhecimentos fundamentais, tem-se os dados bioestratigráficos, em que os fósseis se inserem. Também contemplam os dados relacionados ao estudo da biologia molecular, exemplificados pelos fragmentos de elementos químicos como os ácidos nucleicos, e, por fim, mas não menos importante, os dados da desintegração radioativa que alguns elementos rochosos apresentam.

Grande quantidade de trechos, quarenta e sete (47), aproximadamente 38\%, menciona o estudo dos fósseis, seja ele como base para a datação geológica ou apenas o correlacionando com algum exemplo de espécie extinta ou a características de algum período ou era passada. Uma quantidade pequena trata das datações moleculares (2 trechos) e por radioisótopos (2 trechos).

Entretanto, o que se destaca nessa subcategoria é a quantidade de trechos que não mencionam ou fazem qualquer tipo de relação da datação de tempo geológico com um dos três tipos de conhecimentos mencionados até aqui. Esses fragmentos somam a maior parte dos dados extraídos, totalizando setenta e um (71) trechos, 58\% do total da subcategoria. Nesses exemplos, as coleções oferecem descrições superficiais, carecendo de uma contextualização e aprofundamento necessários, como pode ser verificado no trecho de J2, a seguir:

No século XX, foram desenvolvidos métodos destinados a descobrir a idade das rochas. Com isso, a idade da terra foi calculada em cerca de 4,6 bilhões de anos - muito mais antiga do que imaginavam os cientistas no século XVIII. A história da vida na Terra, por sua vez, teria se iniciado há cerca de 3,5 bilhões de anos (J2, p. 262).

\subsubsection{Intervalos de tempo geológico mencionados}


A Escala de Tempo Geológico é subdividida em quatro intervalos, denominados Eras (Pré-cambriana, Paleozoica, Mesozoica e Cenozoica). Dessas Eras, surgem subdivisões menores, denominadas Períodos, que podem ser divididos em Épocas (Séries) ou intervalos gerais (inferior, médio e superior) (SALGADO-LABOURIAU, 2014). Nesta subcategoria, identificamos nos 122 trechos referentes à 'Noção de tempo profundo', quais os intervalos, em escala geológica, foram mencionados nas coleções investigadas.

Verificou-se que o total, apresentado pelo somatório de todos os intervalos de tempo geológico mencionados explicitamente e os trechos que não mencionam nenhum intervalo, foi de cento e vinte e nove (129) trechos, como se verifica na figura 1 a seguir, apesar de a categoria principal 'Noção de tempo profundo' contar com um total de cento e vinte dois (122) trechos. Essa aparente divergência é explicada pelo fato de alguns poucos trechos mencionarem mais de um intervalo geológico, consequentemente o somatório de intervalos de tempo geológico foi um pouco maior que o de trechos analisados nessa categoria.

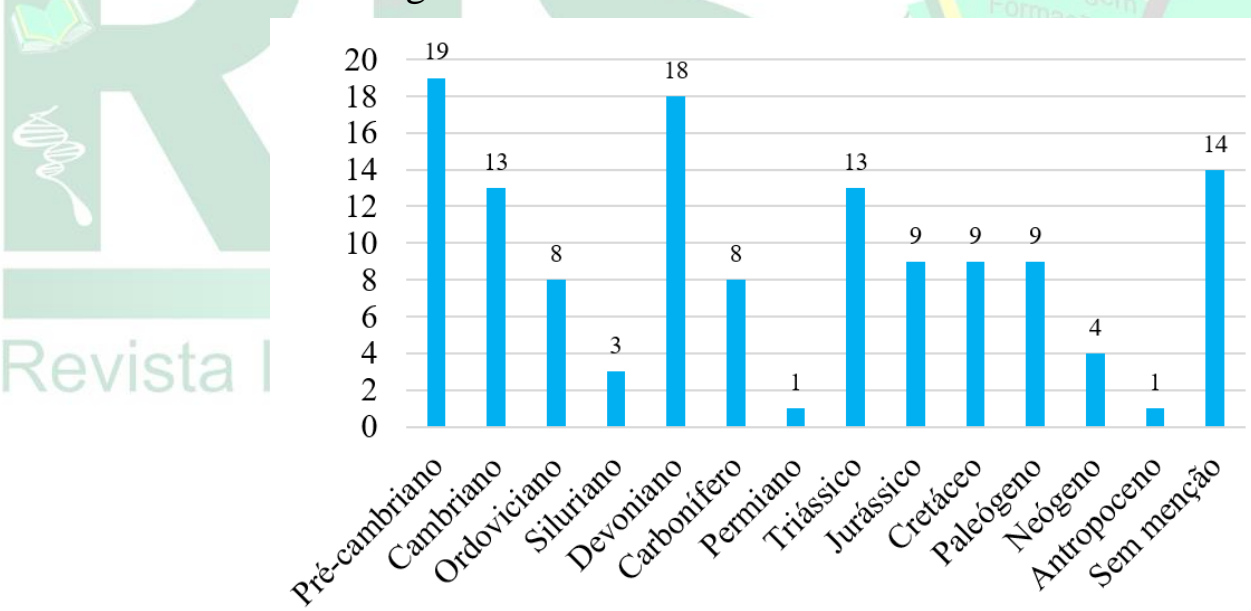

Figura 1 - Gráfico comparativo da quantidade de trechos mencionando os 'intervalos de tempo geológico' na categoria 'Noção de tempo profundo' (Fonte: Elaborado pelos autores)

De maneira geral, ao verificarmos quais foram os intervalos de tempo geológicos mais mencionados, de forma explícita, observamos dentre estes que o Éon Précambriano apresentou maior frequência, dezenove (19) vezes ou $15 \%$, seguido pelos períodos Devoniano, dezoito (18) vezes ou 14\%, Cambriano e Triássico, ambos mencionados treze (13) vezes, representando cada um $10 \%$.

Como já discutiram Oliveira (2006) e Salgado-Laboruriau (2014), o tempo geológico antes do Cambriano é um vasto intervalo de tempo, definido a partir de estudos geoquímicos e geomorfológicos. Contudo, os LD investigados adotam para esse 
intervalo uma denominação genérica, pois o termo "Pré-cambriano" é considerado informal (OLIVEIRA, 2006), uma vez que existem éons geologicamente bem definidos, como o Arqueano e Proterozoico, que compõem esse "pré-cambriano".

Dentre os demais intervalos, o que apresentou menor frequência, na totalidade de trechos da categoria 'Noção de tempo profundo', foram o período Permiano e o Antropoceno, com apenas um (1) trecho cada. Destaca-se que o resultado relativamente baixo apresentado pelo período Permiano, na presente categoria, não reflete sua totalidade nas coleções analisadas, uma vez que outros exemplos desse intervalo encontram-se inseridos na categoria seguinte, 'Eventos macroevolutivos'. No único trecho que se refere ao período Permiano, o LD apresenta-o com uma breve descrição sobre o movimento das placas tectônicas que resultou na união dos continentes, formando a grande massa de terra denominada Pangeia.

Além da baixa frequência e de ser apresentando superficialmente nos LD analisados, no que se refere à categoria 'Noção de tempo profundo', no único exemplo encontrado acerca do período Permiano não se menciona um importante evento macroevolutivo que caracteriza o final desse período: uma das grandes extinções em massa. Como já mencionado anteriormente, ao final desse período ocorreu uma das maiores extinções em massa já conhecida na história da Terra, levando ao desaparecimento de quase toda fauna e flora marinha e terrestre (BENTON, 2012; OLIVEIRA, 2006). Tal extinção iserá observada na categoria seguinte: 'Eventos macroevolutivos'.

Verificou-se, ainda, que uma considerável quantidade, quatorze (14) fragmentos, representando $11 \%$ dos extratos, não apresentou explicitamente a denominação do período descrito. Também de forma mais pulverizada, identificam-se, nas coleções, fragmentos abordando praticamente todos os períodos; no entanto, apesar de parte estar em concordância com a literatura especializada, em alguns LD as descrições se apresentam de forma relativamente superficial, deixando algumas vezes de mencionar aspectos importantes de cada um desses momentos geológicos.

\subsubsection{Atualização do conteúdo}

Nesta subcategoria, a terceira e última a ser analisada na categoria 'Noção de tempo profundo', buscamos investigar nos cento e vinte e dois (122) trechos selecionados na categoria principal, quais destes apresenta conteúdos conceituais 
atualizados, especificamente no que diz respeito aos períodos geológicos. Foram identificados apenas três (3) trechos, presentes em dois volumes de uma única coleção.

Tais trechos falam basicamente acerca de uma nova denominação atribuída ao período final do intervalo do Pré-cambriano e sobre a renomeação do período Quaternário. Esses trechos foram identificados nos livros H2 e H3. Nesse sentido, Viola e Basso (2016) esclarecem que, a partir das interferências do homem na natureza, no período Quaternário foi inserido um novo intervalo geológico, o Antropoceno, exemplo que uma das coleções apresenta a partir de uma breve descrição. Embora tenhamos encontrado algumas atualizações, concluímos que esse aspecto ainda se encontra incipiente nas coleções analisadas em relação à temática investigada.

\subsubsection{Eventos macroevolutivos}

A segunda categoria mais frequente nos LD de Biologia, aprovados no PNLD2018, é a de 'Eventos macroevolutivos', representando cerca de 30\% (70 trechos) do total de fragmentos textuais selecionados. Nessa subseção, buscamos identificar nos trechos investigados quais eventos macroevolutivos são retratados e em qual frequência ocorrem. Nosso foco foram os trechos que apresentem importantes eventos que exemplifiquem a dinâmica dos processos evolutivos na origem dos grandes grupos de seres vivos, tais como a explosão cambriana, a diversificação de diferentes grupos de organismos no ambiente terrestre, a expansão do homem durante o pleistoceno e os conhecidos eventos de extinção em massa.

Organizamos os eventos macroevolutivos identificados no quadro 2 a seguir, em que estão listados, por período geológico, os eventos e sua respectiva frequência. Salientamos que, neste quadro, alguns períodos foram suprimidos em função de não se apresentarem exemplos de eventos macroevolutivos correspondentes a estes períodos nos LD analisados. As grandes extinções em massa estão alocadas no quadro, associadas aos períodos em que o consenso científico afirma que tenham ocorrido.

Quadro 2 - Quantidade de trechos identificados nos LD retratando eventos macroevolutivos relacionados ao período geológico em que ocorreram

\begin{tabular}{|c|c|c|}
\hline $\begin{array}{c}\text { Período } \\
\text { Geológico }\end{array}$ & Eventos Macroevolutivos & $\begin{array}{c}\text { Quantidade de } \\
\text { Trecho } \\
\text { identificado }\end{array}$ \\
\hline Pré-cambriano & Fauna de Ediacara & 3 \\
\hline Cambriano & Explosão Cambriana & 4 \\
\hline Ordoviciano & Irradiação dos Invertebrados & 1 \\
\cline { 2 - 3 } & Extinção em massa & 1 \\
\hline
\end{tabular}




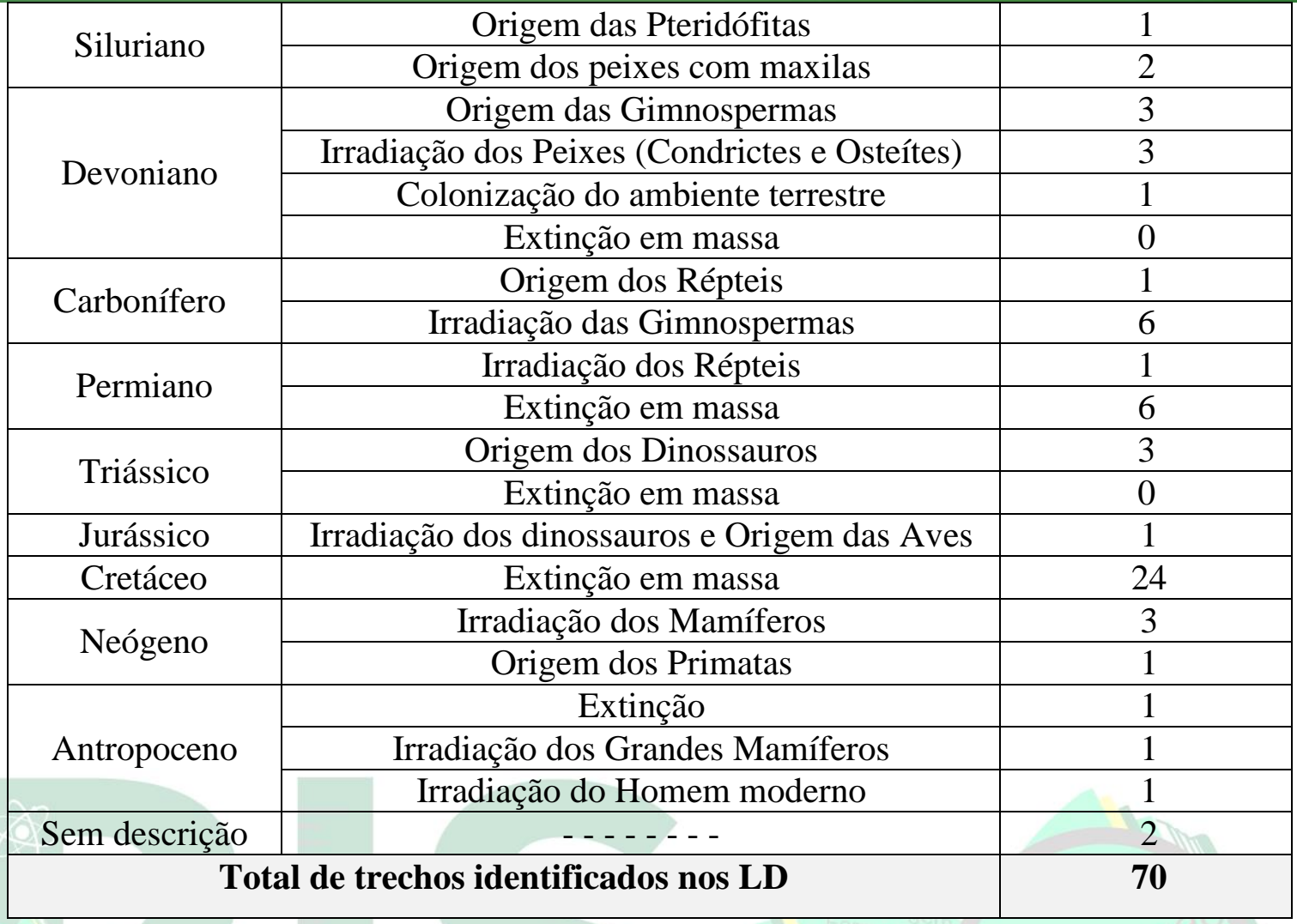

Fonte: Elaborado pelos autores.

Verifica-se que, da totalidade de trechos que tratam sobre Eventos macroevolutivos (70 fragmentos), foram contabilizados vinte e três (23) eventos evolutivos da História da Vida (HV) distintos. Do total de fragmentos (70) da presente categoria, uma significativa parcela, trinta e dois (32) trechos, trata especificamente sobre os eventos de extinção em massa. Apesar desse significativo número, que se aproxima da metade dos fragmentos desta categoria, apenas três, das cinco grandes extinções em massa, são encontradas nos LD analisados, sendo elas: a do final do Permiano, a do Ordoviciano Superior e a do final do Cretáceo. Como esclarecido anteriormente, habitualmente se reconhecem ao menos cinco extinções em massa, sendo elas: a do Ordoviciano Superior (440 milhões de anos), no Devoniano Superior (370 milhões de anos), no fim do Permiano (250 milhões de anos), no fim do Triássico (200 milhões de anos) e no final do Cretáceo (65 milhões de anos) (BENTON, 2012).

Além dessas três, um único trecho, encontrado em C3, apresenta uma sexta extinção, que atingiu apenas um grupo reduzido de animais (os mamíferos gigantes) durante o final do período Pleistoceno, considerado pelo LD como um intervalo em que a Terra passou por uma Era de Glaciação. 
Observa-se que, em relação às extinções em massa, não foram identificados trechos que abordassem as extinções do Devoniano Superior e do final do Triássico. Além disso, enfoque maior é dado à extinção do Cretáceo, em detrimento das outras duas que também aparecem nos LD analisados. Benton (2012) esclarece que a extinção do Cretáceo foi um evento grave que afetou significativamente a evolução da vida, principalmente porque esta possivelmente abriu caminho para que os antepassados distantes dos seres humanos povoassem o ambiente terrestre. Desse modo, esse destaque para a extinção do Cretáceo possivelmente está relacionado com um enfoque antropocêntrico, ainda preponderante nos LD de Biologia para o Ensino Médio, mesmo sendo um aspecto avaliado negativamente pelo PNLD.

\subsubsection{Pensamento filogenético}

A categoria 'Pensamento filogenético' foi a menos frequente dentre todas as categorias analisadas nesta investigação, com quarenta (40) trechos identificados e uma frequência relativa de 17\% dos fragmentos que abordam a História da Vida (HV) nos livros didáticos (LD) de Biologia do PNLD-2018. O parâmetro de análise consistiu na abordagem da história evolutiva dos grandes grupos de seres vivos a partir do conceito de ancestralidade comum e na presença de árvores da vida ou filogenéticas. Desse modo, organizamos a análise a partir de duas subcategorias: 1. Linearidade do Pensamento filogenético; e 2. Pensamento filogenético a partir de árvores da vida.

Na primeira subcategoria figuram os trechos que apresentam a história evolutiva dos grandes grupos a partir de um pensamento linear, denotando a origem de um grupo ou diferentes grupos de seres vivos pela ocorrência da transformação direta de um grupo 'A' em um determinado grupo 'B'. Já a segunda constitui-se de trechos que evitam a perspectiva de linearidade em favorecimento de relações filogenéticas em "árvore" apresentado o grau de parentesco entre espécies atuais e primitivas.

Verifica-se que trechos categorizados como de 'Pensamento Filogenético' estão presentes em oito (8) das dez (10) coleções investigadas, estando ausentes nas coleções 'E' e 'J'. Os trechos que tratam desta categoria se concentram majoritariamente nos livros do segundo ano do Ensino Médio, com vinte e quatro (24) fragmentos, enquanto os livros do primeiro e terceiro ano do Ensino Médio apresentam nove (9) e sete (7) fragmentos, respectivamente. 
Cerca de três quartos, dos 40 trechos, referem-se a uma abordagem filogenética a partir de conceitos como ancestralidade comum e parentesco evolutivo representado por árvores da vida; ou seja, vinte e sete (27) trechos ou 68\%, encaixam-se na segunda subcategoria: 'Pensamento filogenético a partir de árvores da vida'. De acordo com a literatura especializada na área de educação científica, essa abordagem possibilita a problematização de visões distorcidas do processo evolutivo. Para Santos e Calor (2007), o pensamento filogenético, nesse contexto, pode ser utilizado para se evitar, no ensino de Biologia, a noção de que a evolução biológica (EB) é tida como um pensamento unidimensional, ou em escada, em que organismos "progridem" de formas simples para formas dotadas de maior complexidade.

A abordagem dos conteúdos de $\mathrm{HV}$ a partir do pensamento filogenético em "árvores da vida" converte o pensamento linear evolutivo (de A, mais simples, dando origem a B, mais complexo) em uma visão mais refinada, de uma grande árvore, ramificada, situando todos os possíveis graus de parentescos entre os principais grupos de seres vivos. Outra vantagem de estruturar ou abordar fenômenos biológicos, como a origem da biodiversidade, variações de características morfológicas ou de mecanismos fisiológicos, a partir da perspectiva de árvores filogenéticas, é a possiblidade de privilegiar a abordagem de assuntos como tempo geológico, homologias e a noção de evolução como mudança, e não como progresso (SANTOS; KLASSA, 2012).

Os trechos que apresentam essa perspectiva, com pensamento filogenético sendo explicado à luz da sistemática filogenética, possibilitam também a articulação de uma grande quantidade de informações, provenientes de distintos campos da pesquisa biológica, tais como da embriologia, da etologia, da morfologia externa e da fisiologia comparadas, dentre outros. Essa articulação de conhecimentos biológicos vai ao encontro das orientações curriculares oficiais, favorecendo a aprendizagem significativa de conteúdos conceituais outrora apresentados de forma fragmentada.

\section{CONSIDERAÇÕES FINAIS}

Constatamos nessa investigação que os fragmentos textuais analisados descrevem a História de Vida na Terra a partir da identificação dos intervalos de tempo, apresentando as principais mudanças no aspecto físico e biológico característico de cada período, bem como correlacionando dados de outras ciências para explicar como acontece a datação desses intervalos. A contribuição do campo da paleontologia, com a 
abordagem frequente dos registros fósseis nesses fragmentos, é destacadamente presente.

Os dados textuais analisados contemplam praticamente todos os períodos geológicos; no entanto, apesar de boa parte estar de acordo com a literatura especializada, em alguns LD as descrições podem ser consideradas demasiadamente superficiais, deixando algumas vezes de mencionar aspectos importantes de cada um desses momentos geológicos.

Quanto à atualização do conteúdo, identificamos apenas três (3) trechos, presentes em dois volumes de uma mesma coleção, que versavam sobre a introdução, ao final do Pré-Cambriano, do período conhecido como Ediacarano (OLIVEIRA, 2006). Isso não nos leva a inferir que as demais coleções não estão atualizadas ou de acordo com a literatura especializada, mas que na elaboração dos LD a revisão dos conteúdos conceituais é um aspecto que aparentemente está sendo considerado pelas editoras.

Em relação aos eventos macroevolutivos, enfoque maior é dado às extinções em massa. Contudo, destacamos que, além da ausência de duas grandes extinções, a do Devoniano Superior e do fim do Triássico, há uma abordagem relativamente desproporcional da extinção ocorrida no final do Cretáceo, provavelmente pela persistência de uma abordagem antropocêntrica, que precisa ser revista.

Finalmente, com essa investigação esperamos contribuir para a ampliação do conhecimento sobre os LD de Biologia do EM. Assim, para que os conteúdos textuais consigam atender às demandas esperadas por eles no processo de ensino-aprendizagem, novas investigações neste âmbito precisam ser realizadas. Além disso, procuramos com essa investigação (re)avaliar e sugerir que este, e demais estudos semelhantes a este, possam ser levados em consideração na elaboração de novos LD, com a finalidade de atualizá-los e tornar o seu uso realmente efetivo nas aulas de Biologia.

\section{REFERÊNCIAS}

ALMEIDA, A. V.; FALCÃO, J. T. da R. A estrutura histórico-conceitual dos programas de pesquisa de Darwin e Lamarck e sua transposição para o ambiente escolar. Ciência \& Educação, v. 11, n. 1, p. 17-32, 2005.

BARDIN, J. Análise de conteúdo. Lisboa: Edições 70; 1977. 
BIZZO, N.; EL-HANI, C. O arranjo curricular do ensino de evolução e as relações entre os trabalhos de Charles Darwin e Gregor Mendel. Filosofia e História da Biologia, v. 4, n. 1, p. 235-257, 2009.

BRASIL. Base Nacional Comum Curricular (BNCC). Brasília: Ministério da Educação, 2017. Disponível em:<http://basenacionalcomum.mec.gov.br/wpcontent/uploads/2018/ 04/BNCC_EnsinoMedio_embaixa_site.pdf>. Acesso em: 15 de jul. de 2018.

Guia de livros didáticos: PNLD 2018: Biologia. Brasília, Ministério da Educação/Secretaria de Educação Básica, 2017.

BELLINI, L. M. O conceito de evolução nos livros didáticos: avaliação metodológica. Estudos em Avaliação Educacional, n. 33, p. 7-28, 2006.

BENTON, M. J. História da vida. Porto Alegre: Editora L\&PM, 2012.

BONAMINO, A.; MARTÍNEZ, S. A. Diretrizes e parâmetros curriculares nacionais para o ensino fundamental: a participação das instâncias políticas do estado. Educação e Sociedade, Campinas, v. 23, n. 80, p.368-385, set. 2002.

CARMO, V. A.; BIZZO, N.; MARTINS, L. A. P. Alfred Russel Wallace e o princípio de seleção natural. Filosofia e História da Biologia. v.4, p.209-233, 2009.

CERVATO C.; FRODEMAN R. 2014. A importância do tempo geológico: desdobramentos culturais, educacionais e econômicos (tradução). Terra e Didática, 10(1):67-79. Disponível em :<http://www.ige.unicamp.br/terraedidatica/>. Acesso em: 10 jul. 2018.

\section{CICILLINI, G. A. A. A Evolução enquanto um componente metodológico para o} ensino de Biologia no $2^{\mathbf{0}}$ grau: análise da concepção de Evolução nos livros didáticos. 1991. 143f. Dissertação (Mestrado em Educação) - Faculdade de Educação, Universidade Estadual de Campinas, Campinas.

COSTA, V. S. Trazendo a macroevolução para a sala de aula: Ensinando biologia evolutiva de forma pluralista e integrada. 2017. 222 f. Dissertação (Mestrado) - Curso de Licenciatura em Ciências Biológicas, Programa de Pós-graduação em Ensino, Filosofia e História das Ciências, Universidade Federal da Bahia, Salvador, 2017. Disponível em: $<$ https://repositorio.ufba.br/ri/bitstream/ri/23385/1/Dissertação Final - Vanderson Costa.pdf>. Acesso em: 25 mai. 2018.

DAWKINS, R. A grande história da evolução: na trilha dos nossos ancestrais. São Paulo: Companhia das Letras, 2009. 
DIAS, B. C. Macroevolução. 2008. Disponível em: <http://polegaropositor.com.br/ biologia/macroevolucao/>. Acesso em: 11 jul. 2018.

FUTUYMA, D. J. Biologia evolutiva. Ribeirão Preto: FUNPEC-RP, 2006.

GIL, A. C. Como elaborar projetos de pesquisa. 4.ed. São Paulo: Atlas, 2002.

GOODSON, I. F. Currículo: Teoria e História. Petrópolis: Vozes, 1995.

GOULD, S. J. Lance de Dados: a ideia de evolução de Platão a Darwin. Rio de Janeiro: Record, 2001.

Time's Arrow, Time's Cycle: Myth and Metaphor in the Discovery of Geological Time. Cambridge, Ma: Harvard University Press, 1987. 240 p. Disponível em: <http://systematicbiology.co.nf/Goud_Times_ArrowTimesCycle.pdf>. Acesso em: 10 jul. 2018.

HUNEMAN, P. Macroevolution and Microevolution: Issues of Time Scale in Evolutionary Biology. (in) HUNEMAN, P.; BOUTON, C. (eds.), Time of Nature, Nature of Time. Springer, 2015. Disponível em: <https://www.researchgate.net/publication/318137033 Macroevolution_and_Microevolution_Issues_of_Time_Scale_in_Evolutionary_Biology > Acesso em: 11 jul. 2018.

MATIOLI, S. R. Biologia molecular e evolução. Ribeirão Preto: Editora Holos. 2001.

MEYER, D.; EL-HANI, C. N. Evolução: o sentido da biologia. São Paulo: UNESP, 2005.

MINAYO, M. C. de S. (org.). et al. Pesquisa social: teoria, método e criatividade. 4. ed. Petrópolis: Vozes, 2001.

MEGID NETO, J.; FRACALANZA, H. O livro didático de ciências: problemas e soluções. Ciênc. educ. (Bauru) [online]. vol.9, n.2, 2003. Disponível em: <http://www.scielo.br/pdf/ciedu/v9n2/01.pdf> Acesso em: 24 mai. 2018.

OLIVEIRA, J. B. de. O Tempo Geológico no Ensino Fundamental e Médio: os estudantes e os livros didáticos. 2006. 294 f. Tese (Doutorado) - Curso de Biologia, Faculdade de Educação, Universidade de São Paulo, São Paulo, 2006.

OLIVEIRA, M. C. A. de. A origem dos seres vivos na biologia do ensino médio: construindo conhecimentos a partir da dinâmica do júri simulado. In: V Encontro Regional Sul de Ensino de Biologia (EREBIO-Sul) e IV Simpósio Latino Americano e Caribenho de Educação em Ciências do International Council of Associations for Science Education (ICASE). Londrina-PR. Atas... Londrina, 2011. 
RIDLEY, M. Evolução. 3ª ed. Porto Alegre, Artmed, 2006.

ROCHA, P. et al. Brazilian high school biology textbooks: main conceptual problems in evolution and biological diversity. In: Proceedings of the IOSTE International Meeting on Critical Analysis of School Science Textbooks. 2007. p. 893-907.

ROMA, V. N. Os livros didáticos de biologia aprovados pelo programa nacional do livro didático para o ensino médio (PNLEM 2007/2009): a evolução biológica em questão. 2011. 229f. Dissertação (Mestrado em Ensino de Ciências) - Faculdade de Educação, Universidade de São Paulo, São Paulo, 2011.

ROSA, M. D. O livro didático, o currículo e a atividade dos professores de Ciências do Ensino Fundamental. Revista Insignare Scientia - RIS, v.1, n.1, p. 1-20, 2018.

Disponível em: < https://periodicos.uffs.edu.br/index.php/RIS/article/view/7664 >. Acesso em: 15 jun. 2020.

SALGADO-LABOURIAU, M. L. História ecológica da terra. 2. ed. São Paulo: Edgard Blücher Ltda, 2014. 307 p.

SANTOS, C. M. D.; CALOR, A. R. Ensino de biologia evolutiva utilizando a estrutura conceitual da sistemática filogenética - II. Ciência \& Ensino, v. 2, n. 1, 2007.

SANTOS, C. M. D. KLASSA, B. Despersonalizando o ensino de evolução: ênfase nos conceitos através da sistemática filogenética. Educação: Teoria e Prática, v.22, p. 62-81, 2012.

SELLES, S. E. A produção dos BSCS: Livros Didáticos e história da disciplina escolar Biologia. In: Simpósio Internacional - Livro Didático: Educação e História, I, p. 1-17, 2007, São Paulo, SP. Anais...São Paulo: FEUSP, 2007.

TORRES, M. C. A emergência da disciplina biologia escolar (1961-1981): renovação e tradição. Niterói, 2011. 240f. Tese (Doutorado em Educação). Programa de Pós-graduação em Educação, Universidade Federal Fluminense, Niterói, 2011. Disponível em: <http://grupo-de-pesquisa.wix.com/cdc\#!_teses-1> Acesso em:18 ago. 2018.

VASCONCELOS, S. D.; SOUTO, E. O livro didático de ciências no ensino fundamental proposta de critérios para análise do conteúdo zoológico. Ciência \& Educação, v. 9, n.1, p. 104-203, 2003.

VIOLA, E. BASSO, L. O sistema internacional no antropoceno. Rev. bras. Ci. Soc. [online]. 2016, vol.31, n.92, e319201. Epub 29-Ago-2016. ISSN 1806-9053. Disponível em <http://dx.doi.org/10.,17666/319201/2016>. Acesso em: 22 jul. 2018. 
ZAMBERLAN, E. S. J. SILVA, M. R. O evolucionismo como princípio organizador da biologia. Temas \& Matizes, n. 15, p. 27-41, 2009.

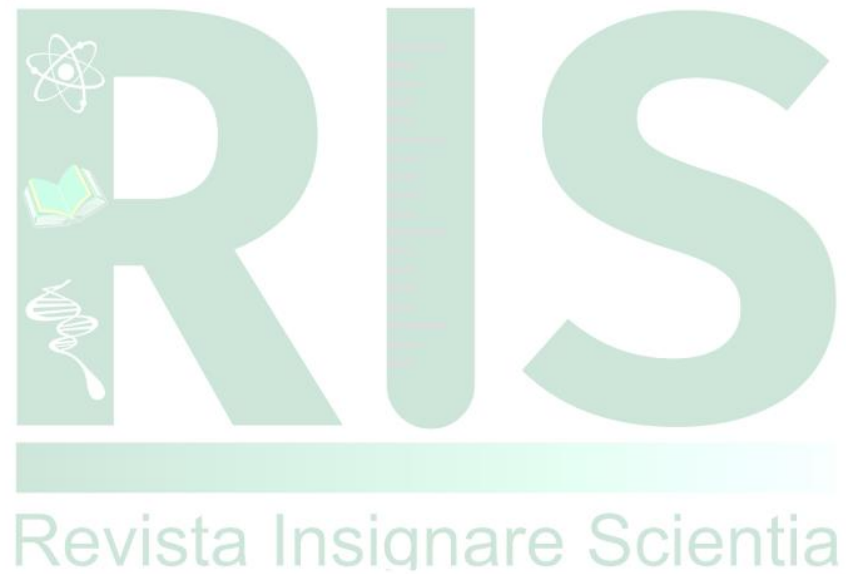

